\title{
A Rare Complication of Central Venous Catheter: Innominant Vein Perforation and Endovascular Treatment
}

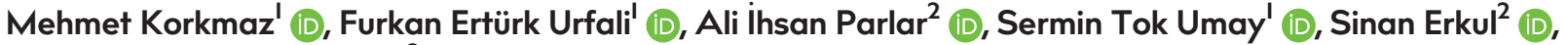 \\ Gülen Sezer Alptekin Erkul ${ }^{2}$ (D)
}

'Department of Radiology, Kütahya Evliya Çelebi Education and Research Hospital, Kütahya, Turkey

${ }^{2}$ Department of Cardiovascular Surgery, Kütahya Evliya Çelebi Education and Research Hospital, Kütahya, Turkey

ORCID iDs of the authors: M.K. 0000-000I-6234-9484; F.E.U. 0000-0002-4875-776l; A.I.P. 0000-000I-5289-602X; S.T.U. 0000-0002716I-016X; S.E. 0000-0002-7990-914X; G.S.A.E. 0000-0003-2838-7828

Cite this article as: Korkmaz M, Urfali FE, Parlar Ai, Umay ST, Erkul S, Erkul GSA. A Rare Complication of Central Venous Catheter: Innominant Vein Perforation and Endovascular Treatment. Cyprus J Med Sci 2021; 6(2): 180-182.

\begin{abstract}
The incidence of central venous catheterization is increasing worldwide. It is important to consult an experienced physician after a failed procedure or in the case of complications. The use of ultrasound during the procedure will increase its success. Left internal jugular vein catheterization is at high risk for vascular injury due to its anatomical position. A 65-year-old female patient with chronic renal failure was referred to our interventional radiology unit with suspected innominant vein perforation. We aimed to present our successful endovascular treatment method in the patient.
\end{abstract}

Keywords: Central venous catheter, venous perforation, coiling

\section{INTRODUCTION}

Central venous catheters are used for different reasons such as hemodialysis, fluid infusion, apheresis, and central venous pressure measurements. Secondary to the advances in medical technologies, prolongation of life expectancy leads to the increase of hypertension and diabetic diseases, and the prevalence of chronic renal failure also causes an increase. Hemodialysis (HD) is the most common renal replacement therapy in patients with chronic renal failure. Due to the low risk of thrombosis and infection, $50 \%$ of patients are treated with mature AV fistula hemodialysis. Temporary catheters are preferred in patients requiring emergency HD treatment and in patients whose catheter is expected to remain for less than 3-4 weeks. Permanent catheters are used in patients with heart failure, peripheral arterial disease, short life expectancy, and severe uremia, which cannot be expected for the maturation of the fistula. The use of a permanent catheter in chronic HD patients is reported as 32\%.' Internal jugular vein and subclavian vein are the first options for central venous catheterization, and femoral vein with a higher risk of mechanical complications is preferred if these veins cannot be accessed. The risk of mechanical complications in central venous catheterization varies between 5 and $19 \%$, where infectious complications occur in 5-26\% and thromboembolic complications occur in 2-26\%. ${ }^{2}$

\section{CASE PRESENTATION}

A 65-year-old female patient who had been followed-up with a diagnosis of chronic renal failure for 15 years underwent left internal jugular vein catheterization for hemodialysis at the outer center. After the procedure because of the absence of blood from the hemodialysis catheter, PA-chest direct radiography was performed. In the radiograph, it is observed that the catheter tip extends to the mediastinum. The patient was evaluated together by our hospital's cardiovascular surgeons and interventional radiologists. It was decided that mediastinal access might be required during the operation and, considering the possible risks, endovascular treatment would be appropriate. The patient's coagulation parameters were within normal limits. The patient was admitted to the angiography unit. A 6F sheath was inserted into the axillary vein, and then a 10 cc 50\% dilated contrast medium was taken from the sheath. We shoved that the hemodialysis catheter was perforated in the innominate vein at the junction of the left internal jugular vein and subclavian vein.

The 5F vertebral catheter passed through the lumen of the hemodialysis catheter, and when the tip extended to the mediastinum, the hemodialysis catheter was slowly removed from the vertebral catheter (Figure I). Then, the coiling was 


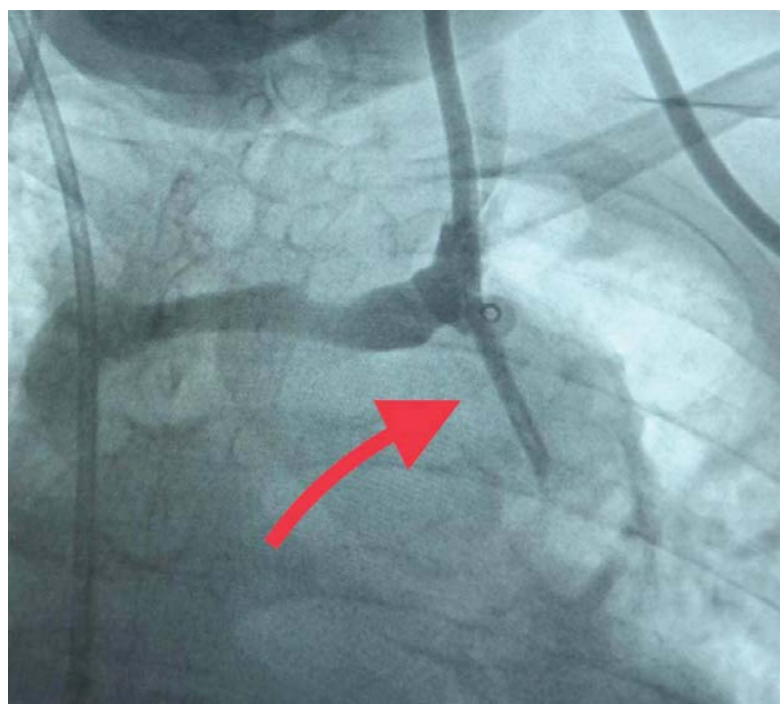

Figure I. 5F vertebral catheter (red curved arrow) extending from the innominant vein to the mediastinum is seen with the contrast material given from the $6 \mathrm{~F}$ sheath in the axillary vein

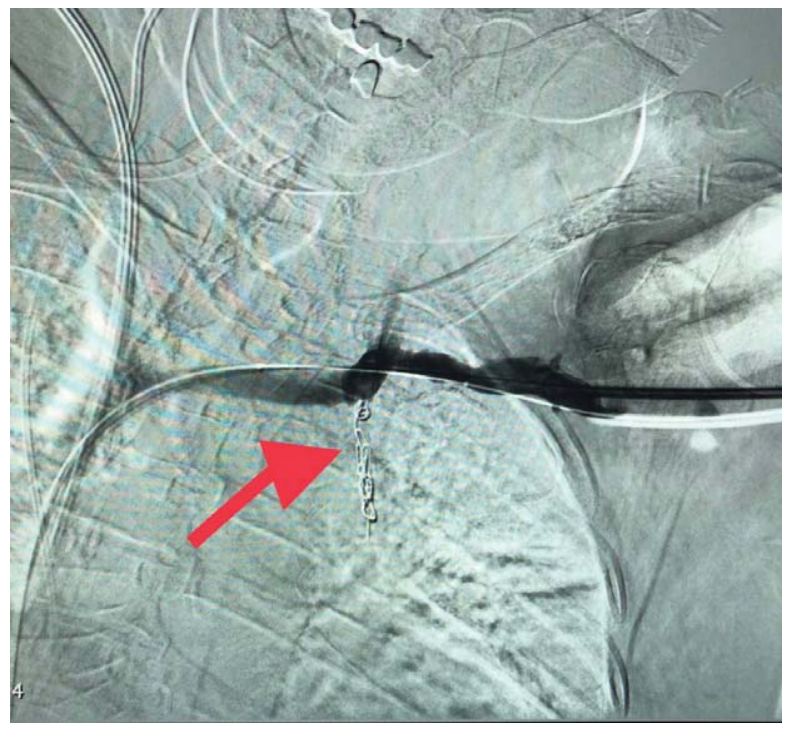

Figure 2. Coil materials (red arrow) extending to the posterior wall of the innominant vein are observed

quickly performed from the distal of the 5F vertebral catheter to the vessel lumen. Coiling was terminated when the distal end of the $5 \mathrm{~F}$ vertebral catheter leaned against the inferior wall of the innominate vein. Afterward, 10 cc 50\% dilated iodin-

\section{Main Points}

- Experience and multidisciplinary approach are important in interventional procedures.

- The risk of complications is lower in procedures performed with imaging.

- Smart decisions can be life-saving in case of complications.

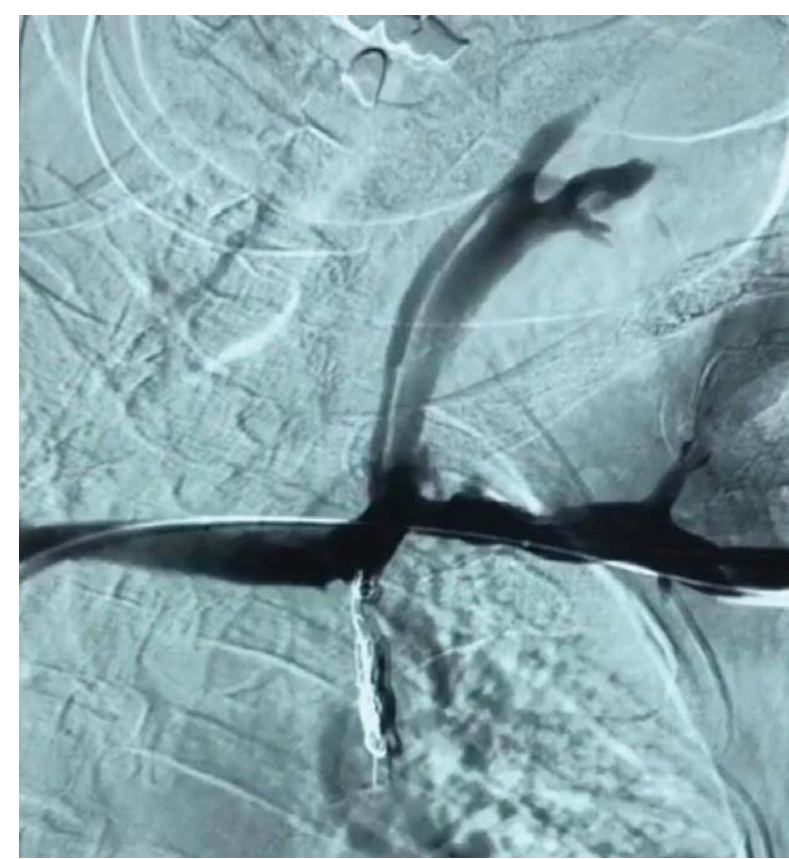

Figure 3. After coiling, the contrast agent given from the $6 \mathrm{~F}$ sheath in the axillary vein showed no extravasation

ated contrast agent injection was performed from the $6 \mathrm{~F}$ sheath in the axillary vein. Angiographic evaluation showed that no contrast agent extravasation and the procedure were terminated by withdrawing the $6 \mathrm{~F}$ sheath and the $5 \mathrm{~F}$ vertebral catheter (Figures 2 and 3 ). Then, a hemodialysis catheter was placed with femoral venous access.

\section{DISCUSSION}

Early complications of central venous catheterization are catheter malposition, catheter fracture, arterial puncture, air embolism, large vessel perforation, pneumothorax-hemothoraxchylothorax, and cardiac arrhythmia, and late complications include central vein thrombosis, development of infection leading to sepsis, and arteriovenous fistula and pseudoaneurysm at the site of intervention. fibrin sheath formation and catheter break (pinch-off syndrome). The risk of complications varies depending on the experience of the person performing the procedure, the weight of the patient, history of radiotherapy or surgical procedures at the site of intervention, and the number of interventions. The ultrasound-guided procedure significantly reduces the risk of complications. ${ }^{3-5}$ Left subclavian and internal jugular vein catheterization are high risk procedures of venous perforation because the innominate vein forms a vertical angle to the SVC. Vascular perforation due to catheter can be seen between days I and 60 after catheter insertion, whereas $50 \%$ occurs on day $2 .{ }^{6}$ Catheter malposition should be suspected in the absence of blood or any other thing such as air, chylous fluid, and nonpulsatile blood. 'Previous case reports have reported that vascular injury/perforation due to catheter malposition is corrected by surgical intervention. ${ }^{8,9}$ In the case report of Singh, it was reported that the patient with innominant vein perforation underwent successful stent graft application with femoral vein access. ${ }^{10}$ In our case, this method was not suitable for our patient because the stent application would prevent the internal jugular vein flow. Central venous 
catheterization should be performed under the control of an experienced physician. Catheter location must be checked by chest X-ray after the procedure. In order to reduce the possibility of complications, it is useful to perform the procedure with ultrasonography.

In conclusion, central venous catheters will continue to be applied with the increasing frequency. Imaging-guided procedures reduce the risk of complications. We believe that this smart method will guide physicians interested in central venous catheterization.

Informed Consent: N/A

Peer-review: Externally peer-reviewed.

Author contributions: Concept - M.K., F.E.U.; Design - S.T.U., A.I.P., S.E.; Supervision - M.K., F.E.U., S.T.U.; Resource - M.K, F.E.U., G.S.A.E.; Materials M.K., F.E.U.; Data Collection and/or Processing - M.K., F.E.U.; Analysis and/or Interpretation - M.K., F.E.U., A.I.P.; Literature Search - M.K., F.E.U.; Writing - M.K., F.E.U.; Critical Reviews - M.K., F.E.U., S.T.U.

Conflict of Interest: Authors have no conflicts of interest to declare.

Financial Disclosure: The authors declared that this study has received no financial support.

\section{REFERENCES}

I. Noordzij M, Jager KJ, Van der Veer SN, et al. Use of vascular access for hemodialysis in Europe: A report from the ERA-EDTA Registry. Nephrol Dial Transplant. 2014;29(I0):1956-1964. [CrossRef]
2. Eisen LA, Narasimhan M, Berger JS, et al. Mechanical complications of central venous catheters. J Intensive Care Med. 2006;2l(I):40-46. [CrossRef]

3. Dariushnia SR, Wallace MJ, Siddiqi NH, et al. Quality improvement guidelines for central venous access. J Vasc Interv Radiol. 2010;2I(7):976-981. [CrossRef]

4. Rabindranath KS, Kumar E, Shail R, et al. Use of real-time ultrasound guidance for the placement of hemodialysis catheters: A systematic review and meta-analysis of randomized controlled trials. Am J Kidney Dis. 2011;58(6):964-970. [CrossRef]

5. Wang CY, Liu K, Chia YY, et al. Bedside ultrasonic detection of massive hemothorax due to superior vena cava perforation after hemodialysis catheter insertion. Acta Anaesthesiol Taiwan. 2009;47(2):95-98. [CrossRef]

6. Duntley P, Siever J, Korwes ML, et al. Vascular erosion by central venous catheters. Clinical features and outcome. Chest. 1992;10I(6):1633-1638. [CrossRef]

7. Stephen M. Rupp MD. Central venous access guideline development and recommendations. IARS. 20ll Review Course Lectures. Available at http://www.iars.org/assets/I/7/II_RCL_Rupp.pdf. Accessed I5 December 2020.

8. Tong MK, Siu YP, Ng YY, et al. Misplacement of a right internal jugular vein hemodialysis catheter into the mediastinum. Hong Kong Med J. 2004;10:135-138.

9. Kaupke CJ, Ahdout J, Vaziri ND, et al. Perforation of the superior vena cava by a subclavian hemodialysis catheter: Early detection by an angiography. Int J Artif Organs. 1992;15(II):666-668. [CrossRef]

10. Singh $V$. latrogenic central vein perforation: A nonsurgical therapeutic approach. Indian J Nephrol. 2019;29(I):42-45. 